\title{
Effects of Ecklonia cava as fucoidan-rich algae on growth performance, nutrient digestibility, intestinal morphology and caecal microflora in weanling pigs
}

\author{
Yohan Choi ', Abdolreza Hosseindoust ${ }^{1}$, Akshat Goel', Suhyup Lee', \\ Pawan Kumar Jha', Ill Kyong Kwon', and Byung-Jo Chae ${ }^{1, *}$
}

\author{
* Corresponding Author: Byung-Jo Chae \\ Tel: +82-33-250-8616; Fax: +82-33-259-5572, \\ E-mail: bjchae@kangwon.ac.kr \\ 'Department of Animal Resources Science, College of \\ Animal Life Sciences, Kangwon National University, \\ Chuncheon 24341, Korea
}

Submitted Feb 5, 2016; Revised Feb 29, 2016; Accepted Apr 14, 2016
Objective: In the present study, role of increasing levels of Ecklonia cava (seaweed) supplementation in diets was investigated on growth performance, coefficient of total tract apparent digestibility (CTTAD) of nutrients, serum immunoglobulins, cecal microflora and intestinal morphology of weanling pigs.

Methods: A total of 200 weaned pigs (Landrace $\times$ Yorkshire $\times$ Duroc; initial body weight $7.08 \pm 0.15 \mathrm{~kg}$ ) were randomly allotted to 4 treatments on the basis of body weight. There were 5 replicate pens in each treatment including 10 pigs of each. Treatments were divided by dietary Ecklonia cava supplementation levels (0\%, 0.05\%, $0.1 \%$, or $0.15 \%)$ in growingfinishing diets. There were 2 diet formulation phases throughout the experiment. The pigs were offered the diets ad libitum for the entire period of experiment in meal form.

Results: The pigs fed with increasing dietary concentrations of Ecklonia cava had linear increase $(p<0.05)$ in the overall average daily gain, however, there were no significant differences in gain to feed ratio, CTTAD of dry matter and crude protein at both phase I and phase II. Digestibility of gross energy was linearly improved $(p<0.05)$ in phase II. At day 28, pigs fed Ecklonia cava had greater (linear, $\mathrm{p}<0.05$ ) Lactobacillus spp., fewer Escherichia coli $(E$. coli) spp. (linear, $\mathrm{p}<0.05)$ and a tendency to have fewer cecal Clostridium spp. $(\mathrm{p}=$ 0.077). The total anaerobic bacteria were not affected with supplementation of Ecklonia cava in diets. Polynomial contrasts analysis revealed that villus height of the ileum exhibited a linear increase $(\mathrm{p}<0.05)$ in response with the increase in the level of dietary Ecklonia cava. However, villus height of duodenum and jejunum, crypt depth, villus height to crypt depth ratio of different segments of the intestine were not affected.

Conclusion: The results suggest that Ecklonia cava had beneficial effects on the growth performance, cecal microflora, and intestinal morphology of weanling pigs.

Keywords: Weanling Pigs, Ecklonia cava, Performance, Gut Microbiota, Gut Morphology

\section{INTRODUCTION}

During the weaning transition undesirable stress accompanied by various changes in the piglet's gastrointestinal environment result in reduced voluntary feed intake [1], which subsequently increases susceptibility to intestinal dysfunction and weaning related disorders [2]. The widespread use of in-feed antibiotics, at both therapeutic and sub-therapeutic levels, increases public health scares [3]. The underlying mechanisms for the growth-promoting effect of antibiotics are expected to relate to gastrointestinal tract, particularly in the small intestine, at the bacteriological, physiological and immunological level [2]. Dietary manipulations post-weaning have the ability to improve weaning associated with intestinal dysfunction.

\section{www.ajas.info}


Marine algae is a good source of biomass, of which, a few types have been identified as rich sources of structurally diverse bioactive compounds with great pharmaceutical and biomedical potential. Presently these identified types are mainly being used for consumption by humans. It is estimated that two-thirds of the earth's biomass is comprised of more than 25,000 species of algae [4]. That statistic shows the potential for algae to be used as animal feed additives due to their vast biodiversity [5] and has recently been discussed as a source of bioactive compounds due to their biological properties [6,7]. Ecklonia cava (E. cava) is among one of the types of seaweed, which is found mainly in South Korea, Japan and China and widely used in human food because of their therapeutic effects. It is a highly resilient brown algae that grows in clear waters [8] and is well known for having fucoidans and polyphenolic compounds (phlorotannins). Fucoidans are branched polysaccharide sulfate esters extracted from the cell wall of marine algae, containing l-fucose as one of the major monosaccharides [9] and they have been shown to have antibacterial [6], immunomodulating [10] and antioxidant [11] activities. Previous researches suggested that $E$. cava can be used as environment friendly substitutes for antibiotics in diets to improve growth in fishes [12] and the immune systems of animals [13]. However, as per our knowledge, not much work has been done to utilize E. cava as feed additive for pigs. In this study, non-antibiotic feed additives are being investigated.

It is hypothesized that the inclusion of $E$. cava will improve the performance of weanling pigs by modifying the gastrointestinal tract microflora, digestibility and immunity. Therefore, the aim of the present experiment is to evaluate the effect of varying dietary inclusion levels of E. cava on the growth performance, coefficient of total tract apparent digestibility (CTTAD) of nutrients, serum immunoglobulins, cecal microflora and intestinal morphology of weanling pigs.

\section{MATERIALS AND METHODS}

The protocol for the present experiment was approved by the Institute of Animal Care and Use Committee of Kangwon National University, Chuncheon, Republic of Korea. The experiment was conducted at the facility of Kangwon National University farm. All the pigs (Landrace $\times$ Yorkshire $\times$ Duroc) were housed in partially slatted concrete floor pens (pen size $1.90 \mathrm{~m} \times 2.54 \mathrm{~m}$ ) which were equipped with self-feeder and nipple drinker to allow ad libitum access to feed and water.

\section{Ecklonia cava collection and processing}

The seaweed E. cava was directly collected from the sea near Jeju Island, washed three times with water to remove the impurities and then dried. The stem was then removed and only leaves were ground to make a particle size of about $100 \mu \mathrm{m}$. This $100 \mu \mathrm{m}$ powder form of E. cava was directly used in the feed. The rate of fucoidan, proportion of monosaccharaides and chemical composition (Table 2) were measured using the previously reported methods [14].

\section{Animals and experimental design}

A total of 200 weaned pigs (Landrace $\times$ Yorkshire $\times$ Duroc; average initial body weight (BW): $7.08 \pm 0.15 \mathrm{~kg}$ ) were randomly allotted to four treatments on the basis of BW and sex (all male or all female). There were five replicate pens in each treatment with 10 pigs per pen. Treatments were divided by dietary E. cava supplementation levels $(0 \%, 0.05 \%, 0.1 \%$, or $0.15 \%)$ in growingfinishing diets. There were 2 diet formulation phases throughout the experiment (Table 1). The diets were prepared in meal form and were formulated to contain $14.22 \mathrm{MJ} / \mathrm{kg}$ metabolism energy (ME) and 1.53\% lysine (phase I; Table 1) and $14.02 \mathrm{MJ} / \mathrm{kg}$ $\mathrm{ME}$ and $14.0 \mathrm{~g} / \mathrm{kg}$ lysine (phase II; Table 1). All diets met or exceeded the nutrient requirements as recommended by [15].

Table 1. Ingredient and chemical composition of basal diets (as-fed basis) ${ }^{1)}$

\begin{tabular}{|c|c|c|}
\hline Item & Phase I (d 0 to 14 ) & Phase II (d 15 to 28) \\
\hline \multicolumn{3}{|l|}{ Ingredient (g/kg) } \\
\hline Corn & 341.3 & 500.8 \\
\hline Whey powder & 200.0 & 153.8 \\
\hline Fish meal & 50.0 & 30.0 \\
\hline SBM dehulled & 232.8 & 229.2 \\
\hline SPC & 50.0 & 30.0 \\
\hline Soy oil & 36.4 & 30.5 \\
\hline MCP & 3.1 & 7.0 \\
\hline Limestone & 6.4 & 8.6 \\
\hline Salt & 2.0 & 2.0 \\
\hline DL-Methionine (980 g/kg) & 1.4 & 1.1 \\
\hline L-Lysine $(780 \mathrm{~g} / \mathrm{kg})$ & 1.6 & 2.0 \\
\hline Vitamin premix $x^{2)}$ & 2.0 & 2.0 \\
\hline Mineral premix $x^{3)}$ & 2.5 & 2.5 \\
\hline Choline-chloride (500 g/kg) & 0.5 & 0.5 \\
\hline Lactose & 70.0 & - \\
\hline Total & 100.00 & 100.00 \\
\hline \multicolumn{3}{|l|}{ Chemical composition (\%) } \\
\hline $\mathrm{ME}(\mathrm{MJ} / \mathrm{kg})$ & 14.22 & 14.02 \\
\hline $\mathrm{CP}$ & 230.0 & 210.0 \\
\hline Calcium & 8.0 & 8.0 \\
\hline Available phosphorous & 4.6 & 4.6 \\
\hline Lysine & 15.3 & 14.0 \\
\hline Met+Cys & 8.7 & 7.9 \\
\hline Lactose & 200.0 & 100.0 \\
\hline
\end{tabular}

SBM, soybean meal; SPC, soy protein concentrate; MCP, mono calcium phosphate; ME, metabolism energy; $C P$, crude proten; Met+Cys, methionine+cysteine.

${ }^{1)}$ The dietary treatments were: Control (basal diet) and basal diet supplemented with 0 , $0.5,1.0$, and $1.5 \mathrm{~g} / \mathrm{kg}$ Ecklonia cava respectively.

${ }^{2)}$ Supplied per kilogram of diet: $20,000 \mathrm{IU}$ vitamin $A, 4,200 \mathrm{IU}$ vitamin $D_{3,}, 10 \mathrm{IU}$ vitamin $E_{1}, 5.6 \mathrm{mg}$ vitamin $\mathrm{K}_{3}, 2.8 \mathrm{mg}$ vitamin $B_{1}, 5.5 \mathrm{mg}$ vitamin $\mathrm{B}_{2}, 4.2 \mathrm{mg}$ vitamin $\mathrm{B}_{61}$ $0.042 \mathrm{mg}$ vitamin $B_{12}, 14 \mathrm{mg}$ pantothenic acid, $42 \mathrm{mg}$ niacin, $0.105 \mathrm{mg}$ biotin, 1.05 $\mathrm{mg}$ folic acid.

3) Supplied per kilogram of diet: $50 \mathrm{mg} \mathrm{Fe}, 0.20 \mathrm{mg} \mathrm{Co,} 30 \mathrm{mg} \mathrm{Cu}, 30 \mathrm{mg} \mathrm{Mn}, 20 \mathrm{mg}$ $\mathrm{Zn}, 0.35 \mathrm{mg} \mathrm{l}, 0.25 \mathrm{mg} \mathrm{Se}$ 
Table 2. Chemical composition of Ecklonia cava

\begin{tabular}{lr}
\hline Items & \\
\hline Component (\%) & \\
$\quad$ Moisture & $8.89 \pm 0.30$ \\
Crude protein & $11.30 \pm 0.63$ \\
Crude fiber & $31.00 \pm 0.72$ \\
Crude lipid & $1.25 \pm 0.19$ \\
Crude ash & $15.60 \pm 0.57$ \\
Carbohydrate & $32.47 \pm 0.57$ \\
Sulfate & $7.88 \pm 0.70$ \\
Fucoidan & $11.2 \pm 0.60$ \\
Proportion of monosaccharides (\%) & \\
Fucose & $47.01 \pm 1.24$ \\
Rhamnose & $1.45 \pm 0.38$ \\
Galactose & $22.05 \pm 0.27$ \\
Glucose & $9.71 \pm 0.10$ \\
Mannose & $4.74 \pm 0.65$ \\
$\quad$ Xylose & $13.96 \pm 1.02$ \\
\hline
\end{tabular}

\section{Sample preparation and measurements}

The pigs were weighed individually at the beginning of the trial, and then at $\mathrm{d} 14$ and $\mathrm{d} 28$ respectively. Consumption of the feed was recorded at the end of each phase. On the bases of these records, average daily gain (ADG), average daily feed intake (ADFI) and gain to feed ratio (G:F) were calculated.

To evaluate the digestibility, $2.5 \mathrm{~g} / \mathrm{kg}$ of chromium was added in the diets as indigestible marker and the diets were fed to pigs during last seven days of each phase. Fecal grab samples were collected randomly from four pigs of each pen during the last three days of each phase. Feces were pooled and dried in an air forced drying oven at $60^{\circ} \mathrm{C}$ for $72 \mathrm{~h}$ and ground in a Wiley laboratory mill (Thomas Model 4 Wiley Mill, Thomas scientific, Swedesboro, NJ, USA) using a 1-mm screen for chemical analysis.

To analyze the concentrations of immunoglobulins (IgG, IgA, and IgM), $10 \mathrm{~mL}$ blood sample was collected from two randomly selected pigs from each pen at d 14 and d 28 of the experiment. The sampling was done by jugular vein puncture using a disposable vacutainer tube without anticoagulants (Becton Dickinson, Franklin, NJ, USA). The blood samples were then centrifuged $\left(3,000 \times \mathrm{g}\right.$ for $\left.15 \mathrm{~min} 4^{\circ} \mathrm{C}\right)$ for serum separation which were then stored at $-20^{\circ} \mathrm{C}$ until analysis.

To study the effect of diets on the small intestinal morphology and cecal microflora, pigs from each treatment (two per replicate) reflecting average BW were selected and sacrificed by electrocution at the end of the experiment (d 28). The cecum contents were collected in sterilized plastic bottles and stored at $7^{\circ} \mathrm{C}$ for bacterial analysis. The intestinal samples from the region of duodenum, jejunum and ileum were also collected after removing their contents and flushing with physiological saline. The samples were submerged in a fixative solution (0.1 $\mathrm{M}$ collidine buffer, $\mathrm{pH}$ 7.3) containing $30 \mathrm{~g} / \mathrm{L}$ glutaraldehyde, $20 \mathrm{~g} / \mathrm{L}$ paraformaldehyde and $15 \mathrm{~g} / \mathrm{L}$ acrolein and then brought to the laboratory for studying the morphological changes.

\section{Chemical and microbial analyses}

Experimental diets and excreta samples were analyzed in triplicate for dry matter (DM, method $930.15 ; 16)$, crude protein (CP, method 990.03; 16), ash (method 942.05; 16), calcium and phosphorus (method 985.01; 16). The gross energy (GE) of diets and feces were measured by a bomb calorimeter (Model 1261, Parr Instrument Co., Moline, IL, USA), and chromium concentration was determined with an automated spectrophotometer (Jasco V-650, Jasco Corp., Tokyo, Japan) according to the procedure of [17]. Amino acid composition of feed samples was determined by HPLC (Waters 486, Waters Corp., Milford, MA, USA) after acid hydrolysis [18]. The methionine and cystine were determined following oxidation with performic acid [19]. The concentrations of serum IgG, IgA, and IgM were analyzed using radial immune-diffusion kits (Tripple J Farms, Bellingham, WA, USA).

The microbiological assay of cecal samples was carried out by the procedure suggested by [20]. One gram of mixed content was diluted with $9 \mathrm{~mL}$ of Butterfields phosphate buffer solution, followed by further serial dilutions in Butterfields phosphate buffer dilution solution. Duplicate plates were then inoculated with $0.1 \mathrm{~mL}$ sample and incubated. The microbial groups enumerated were total anaerobic bacteria (TAB, plate count agar, Difco Laboratories, Detroit, MI, USA), Lactobacillus spp. (MRS agar+0.200 g/L NaN3+0.500 g/L L-cystine hydrochloride monohydrate) and Clostridium spp. (Tryptose sulphite cycloserine agar, Oxoid, Hampshire, UK). The anaerobic conditions during the assay of total anaerobic bacteria and Clostridium spp. were created by using gas-pak anaerobic system (BBL, No. 260678, Difco, Detroit, MI, USA). The microbial populations were log transformed before statistical analysis.

\section{Small intestinal morphology}

Three cross-sections for each intestinal sample were prepared after staining with azure A and eosin using standard paraffin embedding procedures. A total of 10 intact and well-oriented crypt-villus units were selected in triplicate for each intestinal cross-section. Villus height was measured from the tip to the villus crypt junction. Crypt depth was measured as the depth between adjacent villi. All morphological measurements (villus height or crypt depth) were made in $10 \mu \mathrm{m}$ increments by using an image processing and analysis system (Optimus software version 6.5, Media Cybergenetics, North Reading, MA, USA).

\section{Statistical analyses}

The data were analyzed as a randomized complete block design using the general linear model procedure of SAS [21]. The linear and quadratic contrasts were used to compare effect of increasing dietary E. cava levels $(0,0.5,1.0$, and $1.5 \mathrm{~g} / \mathrm{kg})$. The pen was 
Table 3. Effects of supplemental Ecklonia cava on growth performance of weanling pigs

\begin{tabular}{lcccccccc}
\hline \multirow{2}{*}{ Items } & \multicolumn{3}{c}{ Ecklonia cava (\%) } & & \multicolumn{2}{c}{$p$-values } \\
\cline { 2 - 4 } & $\mathbf{0}$ & $\mathbf{0 . 0 5}$ & $\mathbf{0 . 1 0}$ & $\mathbf{0 . 1 5}$ & & & Linear & Quadratic \\
\hline Phase I (d 0 to 14) & & & & & & & \\
ADG (g) & 294 & 297 & 311 & 306 & 8.03 & 0.184 & 0.671 \\
ADFI (g) & 455 & 458 & 468 & 463 & 11.30 & 0.507 & 0.747 \\
G:F & 0.64 & 0.65 & 0.66 & 0.66 & 0.01 & 0.171 & 0.579 \\
Phase II (d 14 to 28) & & & & & & & \\
ADG (g) & 394 & 397 & 426 & 414 & 11.55 & 0.104 & 0.540 \\
ADFI (g) & 645 & 646 & 661 & 662 & 15.38 & 0.350 & 0.989 \\
G:F & 0.61 & 0.61 & 0.65 & 0.63 & 0.01 & 0.248 & 0.437 \\
Overall (d 0 to 28) & & & & & & & \\
ADG (g) & 344 & 347 & 368 & 360 & 7.12 & 0.045 & 0.459 \\
ADFI (g) & 550 & 552 & 565 & 563 & 8.17 & 0.188 & 0.834 \\
G:F & 0.62 & 0.63 & 0.65 & 0.64 & 0.01 & 0.111 & 0.227 \\
\hline
\end{tabular}

$S E M$, standard error of means; $A D G$, average daily gain; $A D F I$, average daily feed intake; $G: F$, gain to feed ratio.

used as the experimental unit for the analysis of all the parameters. Probability values of $\leq 0.05$ were considered as significant.

\section{RESULTS}

\section{Growth performance}

As shown in Table 3, during the phase I and II, there was no significant effects of dietary E. cava on ADG, ADFI, and G:F. A linear response to increasing dietary E. cava was demonstrated for the overall ADG $(\mathrm{p}<0.05)$. However, dietary E. cava did not affect the overall ADFI and G:F.

\section{Digestibility}

Polynomial contrasts analysis showed no significant differences in the CTTAD of GE and CP at both the phases (d 14 and $\mathrm{d} 28$ ), but the digestibility of GE in the second phase linearly improved $(\mathrm{p}<0.05$; Table 4$)$.

\section{Cecal microbial population}

The Pigs supplemented with E. cava in diets showed no effect on the total anaerobic bacteria populations. However, the population of Lactobacillus spp. was linearly increased ( $\mathrm{p}<0.05$; Table 5 ) in pigs supplemented with increasing $E$. cava levels in diets. The population of $E$. coli were linearly reduced ( $\mathrm{p}<0.05$; Table 5) and population of Clostridium spp. tended to decrease ( $\mathrm{p}=$
Table 4. Effects of supplemental Ecklonia cava on apparent total tract digestibility (\%) of nutrients in weanling pigs

\begin{tabular}{ccccccccc}
\hline \multirow{2}{*}{ Item } & \multicolumn{9}{c}{ Ecklonia cava (\%) } & \multirow{2}{c}{ SEM } & \multicolumn{2}{c}{$p$-values } \\
\cline { 2 - 4 } \cline { 7 - 8 } & $\mathbf{0}$ & $\mathbf{0 . 0 5}$ & $\mathbf{0 . 1 0}$ & $\mathbf{0 . 1 5}$ & & Linear & Quadratic \\
\hline D 14 & & & & & & & \\
DM & 81.50 & 81.68 & 82.07 & 81.94 & 1.08 & 0.730 & 0.891 \\
GE & 81.33 & 82.03 & 82.49 & 82.79 & 0.71 & 0.152 & 0.773 \\
CP & 73.02 & 73.25 & 73.56 & 73.20 & 0.73 & 0.796 & 0.687 \\
D 28 & & & & & & & \\
DM & 81.65 & 81.85 & 82.08 & 82.03 & 1.01 & 0.769 & 0.905 \\
GE & 81.14 & 82.69 & 83.86 & 82.99 & 0.73 & 0.042 & 0.093 \\
CP & 73.86 & 73.95 & 74.07 & 74.21 & 0.68 & 0.721 & 1.000 \\
\hline
\end{tabular}

SEM, standard error of means; DM, dry matter; $G E$, gross energy; $C P$, crude protein.

0.077) linearly in E. cava supplemented pigs.

\section{Serum immunoglobulins}

Increasing E. cava level in the diets had no significant effect on serum level of IgG, IgA, and IgM (Table 6) in both phases.

\section{Intestinal morphology}

The diets supplemented with increasing levels of $E$. cava had higher villus height $(\mathrm{p}<0.05$; Table 7$)$ in ileum, but villus height was not affected in other sections of intestine. Crypt depth and villus height to crypt depth ratio was unaffected (Table 7) by supplementation of $E$. cava in diets.

\section{DISCUSSION}

In the recent years, efforts are being made to select new alternatives for feed additives. Seaweeds due to their enormous biodiversity and availability, have the potential to be used for this purpose $[4,5]$. A few of the seaweeds have been tried as feed additives to some extent $[22,23]$, however, the focus of the present study to evaluate the effect of a rich fucoidan ( $E$. cava) supplementation in weanling pigs was significant and meaningful. There was a linear increase in the ADG of the weanling pigs with increasing levels of E. cava. This is in line with the earlier reports of [24] who reported inconsistent, but minimal, performance improvement and increase in ADFI after feeding different seaweeds in pig diet. In contrast, [25] reported the addition of rich fucoidan seaweed to well digestible diets did not enhance performances of weaned piglets.

Table 5. Effects of supplemental Ecklonia cava on caecal microbial populations ( $\log _{10}$ CFU/g) in weanling pigs (d 28)

\begin{tabular}{|c|c|c|c|c|c|c|c|}
\hline \multirow{2}{*}{ Items } & \multicolumn{4}{|c|}{ Ecklonia cava (\%) } & \multirow{2}{*}{ SEM } & \multicolumn{2}{|c|}{ p-value } \\
\hline & 0 & 0.05 & 0.10 & 0.15 & & Linear & Quadratic \\
\hline Total anaerobic bacteria & 8.72 & 8.71 & 8.67 & 8.68 & 0.15 & 0.806 & 0.975 \\
\hline Lactobacillus spp. & 8.35 & 8.45 & 8.64 & 8.61 & 0.11 & 0.049 & 0.508 \\
\hline Clostridium spp. & 7.52 & 7.48 & 7.25 & 7.30 & 0.12 & 0.077 & 0.693 \\
\hline Escherichia coli & 6.44 & 6.34 & 6.15 & 6.18 & 0.10 & 0.043 & 0.524 \\
\hline
\end{tabular}

CFU, colony-forming unit; SEM, standard error of means. 
Table 6. Effects of supplemental Ecklonia cava on serum immunoglobulins ( $\mathrm{mg} / \mathrm{mL})$ of weanling pigs

\begin{tabular}{ccccccccc}
\hline \multirow{2}{*}{ Items } & \multicolumn{9}{c}{ Ecklonia cava (\%) } & & \multicolumn{2}{c}{$p$-value } \\
& $\mathbf{0}$ & $\mathbf{0 . 0 5}$ & $\mathbf{0 . 1 0}$ & $\mathbf{0 . 1 5}$ & & Linear & Quadratic \\
\hline D 14 & & & & & & & \\
IgG & 6.41 & 6.40 & 6.42 & 6.39 & 0.13 & 0.923 & 0.946 \\
IgA & 0.38 & 0.35 & 0.37 & 0.36 & 0.04 & 0.737 & 0.764 \\
IgM & 0.83 & 0.84 & 0.86 & 0.87 & 0.03 & 0.281 & 0.972 \\
D 28 & & & & & & & \\
IgG & 6.34 & 6.40 & 6.38 & 6.41 & 0.11 & 0.745 & 0.927 \\
IgA & 0.33 & 0.35 & 0.36 & 0.34 & 0.04 & 0.889 & 0.605 \\
IgM & 0.84 & 0.86 & 0.87 & 0.88 & 0.03 & 0.385 & 0.899 \\
\hline
\end{tabular}

SEM, standard error of means; Ig, immunoglobulin.

This variation in the results may be due to difference in the seaweed variety and the concentration that was used in the diets. In the present study, ADG was observed to be almost 6\% higher in $1 \mathrm{~g} / \mathrm{kg}$ E. cava supplemented diets in comparison to the control diet. The earlier study of [26] reported a 10\% increase in the BW gain when the diet was supplemented with algae. The greater ADG in pigs fed the E. cava in diets in the present study might be associated with the improvement in GE digestibility and villi height.

In the present study, the digestibility of GE in the second phase was improved. This is in line with the earlier reports of [27] that reported higher digestibility of GE in rich fucoidan seaweed supplemented diets. Increase in the digestibility in the present study, was also accompanied by a slight increase in villi height. A critical role of villi height in the absorption of intestinal nutrients has been reported [28]. Thus, it is more likely that change in the height of villi could be under the influence of the E. cava in the diets that might be responsible for the increase in nutrient uptake and thus resulted in higher digestibility. [29] studied the nutrient digestibility after dietary supplementation of polysaccharides and found a significant

Table 7. Effects of supplemental Ecklonia cava on small intestinal morphology of weanling pigs (d 28)

\begin{tabular}{|c|c|c|c|c|c|c|c|}
\hline \multirow{2}{*}{ Items } & \multicolumn{4}{|c|}{ Ecklonia cava (\%) } & \multirow{2}{*}{ SEM } & \multicolumn{2}{|c|}{ p-values } \\
\hline & 0 & 0.05 & 0.10 & 0.15 & & Linear & Quadratic \\
\hline \multicolumn{8}{|c|}{ Villus height ( $\mu \mathrm{m})$} \\
\hline Duodenum & 438 & 444 & 451 & 446 & 12.08 & 0.591 & 0.713 \\
\hline Jejunum & 402 & 407 & 413 & 404 & 9.32 & 0.811 & 0.454 \\
\hline lleum & 309 & 314 & 324 & 322 & 5.12 & 0.044 & 0.459 \\
\hline \multicolumn{8}{|c|}{ Crypt depth $(\mu \mathrm{m})$} \\
\hline Duodenum & 271 & 260 & 254 & 258 & 9.83 & 0.494 & 0.837 \\
\hline Jejunum & 249 & 258 & 253 & 260 & 11.59 & 0.617 & 0.913 \\
\hline Ileum & 197 & 200 & 208 & 206 & 5.43 & 0.167 & 0.661 \\
\hline \multicolumn{8}{|l|}{$\mathrm{VH}: \mathrm{CD}$} \\
\hline Duodenum & 1.64 & 1.71 & 1.70 & 1.76 & 0.08 & 0.372 & 0.949 \\
\hline Jejunum & 1.63 & 1.59 & 1.65 & 1.58 & 0.09 & 0.809 & 0.878 \\
\hline Ileum & 1.57 & 1.58 & 1.59 & 1.57 & 0.04 & 0.925 & 0.843 \\
\hline
\end{tabular}

SEM, standard error of means; $\mathrm{VH}: \mathrm{CD}$, villus height:crypt depth ratio. interaction between laminaran and fucoidan supplementation on digestibility of GE. Improvement in the digestibility of nutrients and growth performance could be the result of the decrease of harmful bacteria such as E. coli and the increase of friendly bacteria such as Lactobacillus in weanling pigs' microbiota. Lactobacilli are able to produce polysaccharide depolymerases and glycosidases, which can improve the digestibility of nutrients by degrading the structural polysaccharide in plant cell wall [30].

In the present study, supplementation of increasing levels of E. cava did not affect the immune status of the piglets. It has been previously reported that polysaccharides have immunomodulatory activities, and the presence of polysaccharides such as fucoidan in E. cava would most likely be responsible for the immunomodulatory activities [31]. However, the significant effect on immunoglobulins observed in previous work could not be confirmed in the current experiment, it might be because of low dosage of $E$. cava and health status of piglets in this study.

Ecklonia cava, a good source of Fucoidan, a sulfated polysaccharides [27] contains almost $10 \%$ of dry mass of total algae weight. In the present study increasing level of $E$. cava supplementation reduced the Clostridium spp. and E. coli population. This could be due to the presence of sulfated polysaccharides that are well known for their bacterial and viral inhibiting activities [22]. In previous studies, [6] also reported a promising reduction in the coliform populations in the cecum and colon of weaning pigs after supplementing fucoidan extract in diets. Moreover, in earlier studies, [32] reported that polysaccharides can act as prebiotics. Phlorotanin is another important ingredient of E. cava with promising effects against E. coli [33]. In this study, the number of Lactobacillus spp. increased linearly. This could be due to the prebiotic effects of E. cava that may have stimulated the growth of beneficial bacteria in the digestive track and would have exerted growth promoting and health improving effects on the weanling pigs. Moreover, the ratio between these bacterial groups has traditionally been considered as an index of gut health, with a high index related to a greater resistance to intestinal disorders [34]. Therefore, E. cava may offer a dietary means to modulate the gut environment to adjust the intestine microbiota and decrease the risk of diarrhoea in the absence of in-feed antibiotics.

In the present study the villus height in Ileum was linearly improved with increasing levels of $E$. cava supplementation in diets. The linear increase might have aided the nutrient digestion by enhancing the surface area for absorption. The epithelial turnover and villus height have a direct correlation with the nutrient absorption. A similar result was also reported in the previous study when pigs were offered seaweed extracted polysaccharides (laminaran and fucoidan), the villus height and villus height to crypt depth ratio improved [35]. The higher cecal lactobacillus in probiotic-supplemented diet indicated 
greater villus height and villus height to crypt depth ratio in the different small intestinal segments resulted in a greater absorption surface and greater digestibility of nutrients such as crude protein, dry matter and GE [36]. Moreover, the suppression of pathogenic bacteria by favorable bacteria results in the better villus height and villus height to crypt depth ratio [36]. The aid for the favorable microorganisms and hindered growth of unfavorable microorganisms could be one of the reasons behind the better gut morphology.

\section{CONCLUSION}

In conclusion, effects of E. cava on the digestibility of nutrients and intestine morphology were minimal; however, it had a great effect on growth performance and intestinal microbiota. Trends for increased digestibility and villi height will encourage us to try other levels of $E$. cava as effective feed additive on pigs in the future studies.

\section{CONFLICT OF INTEREST}

We certify that there is no conflict of interest with any financial organization regarding the material discussed in the manuscript.

\section{REFERENCES}

1.Pluske JR, Hampson DJ, Williams IH. Factors influencing the structure and function of the small intestine in the weaned pig: a review. Livest Prod Sci 1997;51:215-36.

2.Metzler B, Bauer E, Mosenthin R. Microflora management in the gastrointestinal tract of piglets. Asian-Australas J Anim Sci 2005; 18:1353-62.

3.Williams BA, Verstegen MWA, Tamminga S. Fermentation in the large intestine of single stomached animals and its relationship to animal health. Nutr Res Rev 2001;14:207-27.

4.Henrikson R. Earth Food Spirulina. Ronore Enterprise, Inc, Kenwood, CA; 1997.

5.Hurst D. Marine functional foods and functional ingredients. Oranmore, Galway, Ireland: A briefing document. Marine Institute; 2006. p. 1-72.

6.Reilly P, O'Doherty JV, Pierce KM, et al. The effects of seaweed extract inclusion on gut morphology, selected intestinal microbiota, nutrient digestibility, volatile fatty acid concentrations and the immune status of the weaned pig. Animal 2008;2:1465-73.

7.Islam MM, Ahmed ST, Kim YJ, et al. Effect of sea tangle (Laminaria japonica) and charcoal supplementation as alternatives to antibiotics on growth performance and meat quality of ducks. Asian-Australas J Anim Sci 2014;27:217-24.

8.Kang RS, Won KS, Hong KP, Kim JM. Population studies on the Kelp Ecklonia cava and Eisenia bicyclis in Dokdo, Korea. Algae 2001;16:209-15.

9.Hennequart F, O'Connell EO, Tuohy JS, Tuohy MG. Brown Marco- aglae. Aquafeeds: Formulation and Beyond 2004;1:14-8.

10. Choi YJ, Lee SR, Oh JW. Effects of dietary fermented seaweed and seaweed fusiforme on growth performance, carcass parameters and immunoglobulin concentration in broiler chicks. AsianAustralas. J Anim Sci 2014;27:862-70.

11. Kim JA, Lee JM, Shin DB, Lee NH. The antioxidant activity and tyrosinase inhibitory activity of phlorotannins in Ecklonia cava. Food Sci Biotechnol 2004;13:476-80.

12. Kim K, Kim S, Khosravi S, Rahimnejad S, Lee K. Evaluation of Sargassum fusiforme and Ecklonia cava as dietary additives for olive flounder (Paralichthys olivaceus). Turk J Fish Aquat Sci 2014; 14:321-30.

13. Hwang JA, Islam MM, Ahmed ST, et al. Seamustard (Undaria pinnatifida) improves growth, immunity, fatty acid profile and reduces cholesterol in Hanwoo steers. Asian-Australas J Anim Sci 2014;27:1114-23.

14. Lee SH, Ko CI, Jee Y, Jeong Y, Kim M, Kim JS, Jeon YJ. Anti-inflammatory effect of fucoidan extracted from Ecklonia cava in zebrafish model. Carbohydr Polym 2013;92:84-9.

15. NRC (National Research Council). Nutrient requirements of swine. 11th edn. Washington, DC: National Academies Press; 2012.

16. AOAC (Association of Official Analytical Chemists) International. Official methods of analysis of the Association of Official Analytical Chemists International, 18th edn. Gaithersburg, MD: AOAC International; 2007.

17. Fenton TW, Fenton M. An improved procedure for the determination of chromic oxide in feed and feces. Can J Anim Sci 1979;59:631-63.

18. Knabe DA, LaRue DC, Gregg EJ, Martinez GM, Tanksley Jr TD. Apparent digestibility of nitrogen and amino acids in protein feed stuffs by growing pigs. J Anim Sci 1989;67:441-58.

19. Moore S. On the determination of cystine as a cysteic acid. J Biol Chem 1963;238:235-37.

20. Torrallardona D, Conde MR, Badiola I, Polo J, Brufau J. Effect of fishmeal replacement with spray-dried animal plasma and colistin on intestinal structure, intestinal microbiology, and performance of weanling pigs challenged with Escherichia coli K99. J Anim Sci 2003;81:1220-6.

21. SAS (Statistical Analysis System) Institute Inc. SAS Software for PC. Release 9.3, Cart, NC: SAS Institute Inc; 2012.

22. Leonard SG, Sweeney T, Pierce KM, et al. The effects of supplementing the diet of the sow with seaweed extracts and fish oil on aspects of gastrointestinal health and performance of the weaned piglet. Livest Sci 2010;134:135-8.

23. Hong ZS, Kim EJ, Jin YC, et al. Effects of supplementing brown seaweed by-products in the diet of Holstein cows during transition on ruminal fermentation, growth performance and endocrine responses. Asian-Australas J Anim Sci 2015;28:1296-302.

24. Turner JL, Dritz SS, Higgins JJ, Minton JE. Effect of Ascophyllum nodosum extract on growth performance and immune function of young pigs challenged with Salmonella typhimurium. J Anim Sci 2002;80:1947-53. 
25. Michiels J, Skrivanova E, Missotten J, et al. Intact brown seaweed (Ascophyllum nodosum) in diets of weaned piglets: effects on performance, gut bacteria and morphology and plasma oxidative status. J Anim Physiol Anim Nutr 2012;96:1101-11.

26. He ML, Hollwich W, Rambeck WA. Supplementation of algae to the diet of pigs: a new possibility to improve the iodine content in the meat. J Anim Physiol Anim Nutr 2002;86:97-104.

27. O'Doherty JV, Dillon S, Figat S, Callan JJ, Sweeney T. The effects of lactose inclusion and seaweed extract derived from Laminaria spp. on performance, digestibility of diet components and microbial populations in newly weaned pigs. Anim Feed Sci Technol 2010; 157:173-80.

28. Mekbungwan A, Yamauchi KE, Thongwittaya N. Intestinal morphology and enteral nutrient absorption of pigeon pea seed meal in piglets. Anim Sci J 2002;73:509-16.

29. Walsh AM, Sweeney T, O'Shea CJ, Doyle DN, O'Doherty JV. Effect of supplementing different ratios of laminarin and fucoidan in the diet of the weanling piglet on performance, nutrient digestibility, and fecal scoring. J Anim Sci 2012a;90:215-7.

30. Macfarlane GT, Hay S, Macfarlane S, Gibson GR. Effect of different carbohydrates on growth, polysaccharidase and glycosidase production by Bacteroides ovatus, in batch and continuous culture. J
Appl Microbiol 1990;68:179-87.

31. Castro R, Zarra I, Lamas J. Water soluble seaweed extracts modulate the respiratory burst activity of turbot phagocytes. Aquaculture 2004;229:67-78.

32. Vidanarachchi JK, Iji PA, Mikkelsen LL, Sims I, Choct M. Isolation and characterization of water-soluble prebiotic compounds from Australian and New Zealand plants. Carbohydr Polym 2009;77: 670-6.

33. Wang Y, Xu Z, Bach SJ, McAllister TA. Sensitivity of Escherichia coli to seaweed (Ascophyllum nodosum) phlorotannins and terrestrial tannins. Asian-Australas J Anim Sci 2009;22:238-45.

34. Ewing G, Cole DJA. The living gut: an introduction to microorganisms in nutrition. Dungannon, UK: Context Publications; 1994.

35. Walsh AM, Sweeney T, O'Shea CJ, Doyle DN, O'Doherty JV. Effects of supplementing dietary laminarin and fucoidan on intestinal morphology and the immune gene expression in the weaned pig. J Anim Sci 2012b;90:284-6.

36. Lei X, Piao X, Ru Y, Zhang H, Peron A, Zhang H. Effect of bacillus amyloliquefaciens-based direct-fed microbial on performance, nutrient utilization, intestinal morphology and cecal microflora in broiler chickens. Asian-Australas J Anim Sci 2015;28:239-46. 